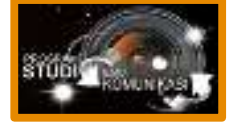

\title{
STRATEGI KOMUNIKASI POLITIK TIM KAMPANYE DAERAH JOKO WIDODO - K.H. MA'RUF AMIN PROVINSI JAWA TIMUR PEMENANGAN PILPRES 2019
}

\author{
Dafis Ubaidillah Assiddiq ${ }^{1}$ | Dewi Ambarwati ${ }^{1}$
}

1Program Studi IImu Pemerintahan, Universitas Islam Raden Rahmat Malang

Jl. Raya Mojosari No.2 Kepanjen, Kabupaten Malang, Jawa Timur 65163

Correspondence:

Dafis Ubaidillah Assiddiq

dafis@uniramalang.ac.id

\begin{abstract}
This study aims to discuss how the Regional Campaign Team (TKD) Ir. Joko Widodo - KH. Ma'ruf Amin of East Java Province in formulating the strategy of the East Java TKD funds of local officials, Jokowi's volunteer network and East Java kyais and political figures to win the Candidate Candidate No.1.In this study several resource persons stated that the role of all elements of society and figures and clerics and in the 2019 presidential election were very compact and effective, especially with the many issues of ethnicity, race and religion, which were used to attack incumbent Joko Widodo. This type of research uses descriptive qualitative methods and case study methods, with data collection techniques, namely interviews and documentation. The purpose of this research is to describe the Strategy of the East Java Regional Campaign Team Joko Widodo - KH. Ma'ruf Amin and Jokowi Volunteers during the Presidential election, therefore the East Java TKD strategy is an opinion leader to determine the Getter vote and become a political mediator to various parties who have an important role to increase votes in East Java.
\end{abstract}

Keywords: Regional Campaign Team, Political Strategy, Presidential Election

\begin{abstract}
Abstrak: Penelitian ini bertujuan untuk membahas bagaimana Tim Kampanye Daerah (TKD) Ir. Joko Widodo - KH. Ma'ruf Amin Provinsi Jawa Timur dalam menyusun Strategi apa yang dilakukan oleh TKD Jawa Timur dana pejabat daerah, jaringan Relawan Jokowi serta para kyai dan tokoh politik Jawa Timur untuk memenangkan Paslon No 1. Dalam penelitian ini beberapa nara sumber menyatakan bahwa peran seluruh elemen masyarakat dan tokoh dan para kyai danalam pemilihan presiden pada tahun 2019 ini begitu sangat kompak dan efektif, terlebih dengan banyaknya isu Suku Ras dan Agama yang dugunakan untuk menyerang incumbent Joko Widodo. Jenis penelitian ini menggunakan metode kulaitatif deskriptif dan medote studi kasus, dengan teknik pengumpulan data yaitu wawancara dan dokumentasi. Hasil penelitian ini adalah strategi Tim Kampanye Daerah Jawa Timur Joko Widodo - KH. Ma'ruf Amin dan Relawan Jokowi menggunakan strayer saat pemilihan Presiden, oleh sebab itu strategi TKD Jatim menjadi penentu (opinion leader) untuk menentukan vote Getter dan menjadi mediator politik ke berbagai pihak yang mempunyai peranan penting untuk meningkatkan suara di Jawa timur.
\end{abstract}

Kata Kunci: Tim Kampanye Daerah, Strategi Politik, Pemilihan Presiden 


\section{1 | PENDAHULUAN}

Indonesia telah melakukan pemilu yang ke empat pasca reformasi,kali ini pesta demokrasi pada tahun 2019 dilakukan secara serentak, Pemilihan Legeslatif (PILEG) dan Pemilihan Presiden (Pilpres) Republik Indonesia. Data dari KPU Jatim (2019) Pilpres 2019 di ikuti oleh Tiga belas (13) Partai Politik dengan dua Calon Presiden dan Wapres. Adapun komposisi partisipasi partai dalam memberikan dukungan terhadap pasangan calon pimpinan negara nomor 01 Jokowi-Ma'ruf didukung 9 partai, dan nomor 02 Prabowo-Sandiaga didukung 4 partai.

Jokowi-Ma'ruf : PDI-P,PKB.Nasdem, Golkar, PPP,PKPI,Hanura, PKPI, PSI

- Prabowo-Sandiada: Gerindra, PKSm PAN, Demokrat

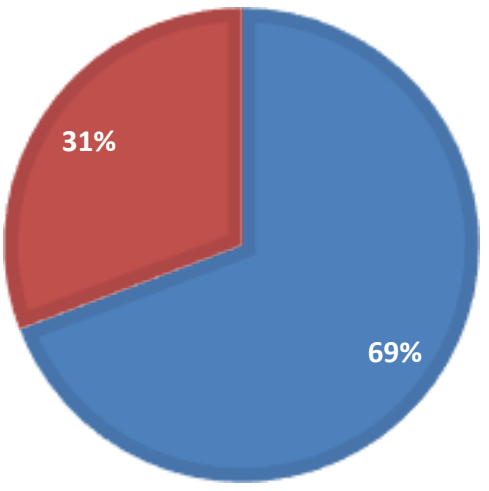

Gambar 1. Komposisi Partisipasi Partai dalam Pilpres 2019 (KPU, 2019)

Komisi Pemilihan Umum pada tanggal 22 mei 2019 secara resmi mengumumkan hasil rekapitulasi Pemilihan Presiden secara Nasional, dengan hasil perolehan $55 \%$ suara diperoleh oleh Joko Widodo - KH. Ma'ruf Amin dan untuk prabowo Subianto - Sandiago Uno memperoleh suara sebesar 44,50 \%. Paslon No 1 Joko widodo \& KH. Ma'ruf Amin memperoleh suara terbanyak, suara terbanyak paslon no 01 diperoleh dari provinsi Jawa Tengah sebesar 16.825.511 dan susra terbanyak kedua diperoleh dari Provinsi jawa timur sebesar 16.231.668 (KPU, 2019). Untuk mendapatkan suara yang maksismal merupakan serangkaian upaya dari Tim kampanye Daerah yang memiliki tujuan yang sama yaitu memenangkan pasangan Joko Widodo dan $\mathrm{KH}$. Maruf Amin dalam pemilihan Presiden 2019. Sesuatu yang menarik untuk dibahas adalah mengenai Strategi komunikasi Politik yang dilakukan oleh Tim Kampanye Daerah (TKD) yang dilakukan untuk menarik suara dari masyarakat.

Tim Kampanye Daerah Joko Widodo - KH. Ma'ruf Amin Wilayah Jawa Timur Mengajak seluruh komponen-komponen penting diantaranya para Kyai, Relawan dan Partai Koalisi untuk turut bersama sama memenangkan Paslon No 1 Joko Widodo - KH. Ma'ruf Amin. Isu yang menarik dalam pertarungan Pilpres 2019 adalah dimana sebelum dilakukanya hari pencoblosan atau pemungutan suara pada tanggal 17 April 2019 yang mana calon presiden yang juga merupakan petahana (incumbent), Joko Widodo diserang dengan berbagai banyak isu Suku, Ras, dan Agama (SARA). Diantaranya adalah Presiden Anti Islam. Presiden Antek Cina, Presiden Komunis, Presiden yang telah melakukan kriminalisasi terhadap ulama, kemudian banyaknya tenaga kerja Asing yang masuk di Indonesia, yang dilakukan secara intens dan sangat massif oleh pihak tertentu.

Proses demokrasi bisa dideskripsikan melalui berbagai ajang pemilihan kepala daerah terutama bisa direpresentasikan melalui pemilihan presiden. Kemenangan berbagai calon dalam 
pilkada terdapat konstelasi pragmatis atas praktik politik di dalamnya (Fatchuriza, \& Prasojo, 2019; Noor, 2018). Kajian yang senada adalah strategi kampenye difokuskan pada strategi konstruksi citra (Hasyim, 2016; Leiliyanti et al., 2017). Strategi pemenangan pesta politik pada dasarnya dalam Pusparimba et al., (2021) dijelaskan untuk menampilkan sosok tokoh yang memiliki citra kerakyatan, disukai, jujur dan berideologi dominan demokrasi. Proses komunikasi politik melalui berbagai sgtrategi kampanye dalam studi Dicky (2020) di Minangkabau menciptakan sebuah budaya politik tersendiri yakni 3T (Takah,Tageh,Tokoh).

\section{Komunikasi Politik}

Definisi komunikasi politik merupakan rangkaian proses interaktif yang mengenai penyebaran informasi antara para politisi, media berita dan publik. Dimana proses tersebut bekerja dari atas ke bawah yaitu dari institusi ke warga secara horisontal yang akan menghubungkan para aktor politik, dan juga bekerja dari bawah ke atas yakni dari opini publik ke penguasa (Fatimah, 2018; Noris \& Phillips., 2003) .

Selain itu dapat dipahami bahwa komunikasi politik juga merupakan sebuah proses pengoperasian lambang-lambang atau simbol-simbol komunikasi yang berisi pesan-pesan politik dari seseorang atau kelompok kepada orang lain dengan tujuan untuk membuka wawasan atau cara berfikir, serta mempengaruhi sikap dan tingkah laku khalayak yang menjadi target politik (Cangara, 2014).

Merujuk pada Nimmo yang dikutip oleh Suwardi et al., (2012) terdapat 2 artian dari komunikasi politik, yaitu arti luas dan arti sempit. Arti sempit yang meliputi komunikasi politik ini sebagai suatu komunikasi yang dikategorikan mempunyai nilai atau bobot politik, apabila komunikasi yang dimaksud mempunyai konsekuensi atau akibat politik yang mengatur tingkah laku manusia dibawah kondisi pertentangan (konflik). Sedangkan dalam arti luasnya, komunikasi politik setiap jenis penyampaian pesan, khususnya yang bermuatan politik dari suatu sumber ke sejumlah penerima.

Dalam praktik komunikasi politik, proses pembentukan citra politik diilakukan dengan cara mengemas pesan politik untuk disebarkan kepada masyarakat. Kemudian media massa dijadikan bagian dari instrumen pembentukan dan penyampaian pesan politik tersebut. Gambaran ini yang disebut stayer sebagai bagian dari cara baru dalam mengkomunikasikan politik (Hasfi, 2019; Suryadi et al., 2021; Waluyo, 2019). Pengguaan web dalam meningkatkan mengurangi gangguan sekaligus menambah ganguan dalam proses komunikasi (Triono \& Setiyaningsih, 2017).

\section{Kampanye Sebagai Strategi Komunikasi Politik}

Strategi Komunikasi Politik merupakan tentang bagaimana proses komunikasi yang terjadi di dalam pemenangan pertarungan politik oleh partai politik, atau secara langsung, oleh seorang calon legislatif atau calon pemimpin daerah, dan pemimpin negara yang mengehendaki kekuasan dan pengaruh sebesar-besarnya ditengah-tengah masyarakat sebagai konstituennya (Sugiarto, \& Pratiwi, 2014).

Ada dua bentuk strategi komunikasi politik, yaitu: Pertama, strategi komunikasi politik yang cenderung mengambil posisi horisontal. Dalam hal ini posisi antara komunikator politik dan masyarakat sebagai komunikan relatif seimbang sehingga terjadi pemberian dan penerimaan informasi, bentuk strategi semacam ini merupakan refleksi nilai-nilai demokratis. Kedua, strategi komunikasi politik yang cenderung membentuk pola linier. Arus komunikasi satu arah cenderung vertikal (top-down). Bentuk seperti ini merefleksikan nilai-nilai budaya feodalistik dan kepemimpinan otoriter (Aurellia, 2021; Sultoni, \& Harsasto, 2020; Triwicaksono, \& Nugroho, 2021). 
Strategi Komunikasi memiliki fungsi ganda. Pertama, untuk menyebarluaskan pesan komunikasi yang bersifat informatif, persuasif, instruktif secara sistematis kepada sasaran untuk memperoleh hasil yang maksimal. Sedangkan fungsi yang kedua adalah untuk mejembatani kesenjangan budaya akibat kemudahan diperolehnya dan dioperasionalkannya media massa yang begitu ampuh, yang jika dibiarkan akan merusak nilai-nilai budaya (Sanjaya et al., 2016).

Penjelasan dalam Antar (2004) mendefinisikan kampanye sebagai serangkaian kegiatan komunikasi yang terorganisasi dengan tujuan untuk menciptakan dampak tertentu terhadap sebagian besar khalayak sasaran secara berkelanjutan dalam periode waktu tertetu. Sedangkan Pau dan Parrot (1993) dalam Antar (2004) mendefinisikan kampanye sebagai kegiatan yang dilakukan secara sadar untuk menunjang dan meningkatkan proses pelaksanan yang terencana pada periode tertentu yang bertujuan mempengaruhi khalayak tertentu.

Dalam Pura (2019) mengartikan sebuah kampanye komunikasi merupakan aktivitas komunikasi yang terorganisasi, secara langsung ditujukan kepada khalayak tertentu, pada periode waktu yang telah ditetapkan untuk mencapai tujuan tertentu. Dengan demikian dapat diidentifikasi bahwa aktivitas kampanye paling tidak mengandung empat hal yakni, pertama ditujukan untuk menciptakan efek atau dampak tertentu, kedua ditujukan kepada jumlah khalayak sasaran yang besar, ketiga dipusatkan dalam kurun waktu tertentu, dan yang keempat dilakukan melalui serangkaian tindakan komunikasi yang terorganisasi.

Untuk menganalisa Strategi Komunikasi politik tim kampanye daerah Jawa Timur Joko Widodo dan KH. Ma'ruf Amin, Penulis menggunakan model of political marketing Neuman et al., (1992) menggambarkan Tim sukses dari kandidat tertentu dapat menggunakan berbagai alat pemasaran. Kala itu model ini diterapkan pada saat kampanye pemilihan presiden calon kandidat Bill Clinton di negara Amerika Serikat pada tahun 1992. Di saat itu Newman juga berpendapat bahwa dengan membangun kampanye yang berorientasi pasar dengan kata lain menyerahkan diri kepada keinginan dan kebutuhan masyarakat dan mengesampingkan keinginan pribadi maka penyampaian pesan lebih efektif oleh karena itu mempermudah membangun bingkai komunikasi politik.

\section{2 | METODE PENELITIAN}

Penelitian ini menggunakan pendekatan kualitatif deskriptif. Dalam Moleong (2014) kualitatif merupakan prosedur penelitian yang menghasilkan data deskriptif berupa kata-kata tertulis atau lisan dari orang-orang dan perilaku yang dapat diamati. Penelitian ini juga menggunakan metode studi kasus untuk mengetahui lebih mendalam mengenai peran strategi komunikasi politik tim kampanye daerah wilayah Jawa Tengah Joko Widodo dan $\mathrm{KH}$. Ma'ruf Amin pada pemilihan presiden 2019. Penelitian ini menggunakan pusposive sampling, dengan maksud untuk memberikan kriteria kepada informan dalam penggalian data. Informan yang dilibatkan adalah 5 orang tim inti pemenangan kampanye jokowi-ma'ruf di Jawa Tengah. Teknik pengumpulan data dengan melalui observasi dan wawancara. Data yang diperoleh dianalisis menggunakan analisis data Miles \& Huberman (2014) yakni pengumpulan data, penyajian data, reduksi data dan verifikasi serta menarik kesimpulan. 


\section{3 | HASIL DAN PEMBAHASAN}

\section{Implementasi Kampanye TKD Joko Widodo dan KH. Ma'ruf Amin di Jawa Timur}

Posisi TKD Jawa Timur dalam pelaksanaan strategi pemenangan dalam meraih suara Nahdliyin adalah sebagai harmonisator. TKD bertugas untuk menjaga harmoni antara JKSN dengan relawan lain agar tidak tumpeng tindih. Sementara JKSN sendiri adalah eksekutor pemenangan dalam hal meraih suara Nahdliyin. Anggota JKSN yang sangat beperan aktif adalah Kiai Asep Saifudin Khalim yang merupakan cucu salah satu pendiri NU (tirto.id, 2019). Kiai Khalim ini yang banyak melakukan komunikasi kepada banyak Kiai untuk ikut melakukan pemenangan 01.

Pada dasarnya peran Kiai Asep ini bukan hanya langsung kepada Kiai-Kiai yang menjadi relawan di lapangan, namun juga menjadi komando dari JKD tiap-tiap daerah. Karena sejak JKSN ini ada hanya untuk memenangkan Khofifah - Emil juga Kiai Asep yang banyak berperan. Dari JKD tiap-tiap daerah ini kemudian mencoba memengaruhi semua kalangan Kiai yang ada di tiap-tiap daerah untuk melakukan upaya pemenangan. Jika dipetakan menurut Endang Turmudi, setidaknya ada empat jenis Kiai yang disasar oleh JKD. Kiai Pesantren, Kiai Tarekat, Kiai Politik, dan Kiai Panggung. Meskipun ada empat jenis Kiai. Jika diamati seringkali satu Kiai bisa memiliki dua kriteria Kiai sekaligus. Misalnya saja Kiai Asep bukan hanya seorang Kiai Pesantren, namun juga Kiai Politik. Begitu juga dengan Kiai-Kiai lain, banyak yang termasuk Kiai Tarekat sekaligus Kiai Pesantren.

Kiai Pesantren dan Kiai Tarekat inilah yang kemudian banyak disebut sebagai Kiai Kampung. Kata pesantren sebenarnya bukan hanya pesantren dalam artian sebenarnya saja. Namun juga Kiai yang ada di musholla, masjid, dan sebagainya. Kiai-Kiai yang berada di pesantren dalam artian sebenarnya, dan di tempat-tempat seperti Mushola dan Masjid itulah yang dianggap lebih memiiliki masa yang banyak daripada ulama- ulama yang sering muncul di televisi, sebagaimana banyak digunakan oleh kubu 02.

Dari pengakuan salah satu responden, diketahui bahwa pada awalnya banyak tokoh NU yang merupakan bagian dari Kiai Kampung ini tidak mau bergerak. Namun mereka memberikan setidaknya dua jenis suntikan motivasi. Yang pertama adalah bahwa jika mereka tidak ikut memilih Kiai Ma'ruf Amin dalam pilpres 2019, maka mereka sama saja dengan menginjak-injak kepala NU. Lalu yang kedua, mereka mengajak Kiai Kampung untuk ikut bergerak karena ada kekuatan kelompok Islam Radikal yang ingin berkuasa. Jika Kiai-Kiai tidak mau bergerak, maka ahlussunnah wal jamaah akan terancam, mereka harus bergerak agar ajaran ini tetap lestari di bumi dan tidak kalah dengan kekuatan kelompok radikal yang berada di balik pendukung Prabowo.

Dengan suntikan motivasi yang seperti ini akhirnya tokoh- tokoh NU yang diantaranya merupakan Kiai Kampung bersama-sama bergerak untuk memenangkan 01. Pada mulanya KiaiKiai Kampung ini diajak untuk melakukan berbegai deklarasi pemenangan yang biasanya bertempat di kediaman Kiai Asep. Lalu setelah itu mereka melakukan upaya memengaruhi Nahdliyin melalui pangung-panggung, door to door dan melalui acara di pondok pesantren.

Penggerak utama di lapangan yang menyasar langsung Nahdliyin dari kalangan akar rumput bukan hanya dari keempat jenis Kiai yang telah disebutkan tersebut. Melainkan juga dari pergerakan santri. Santri ini diantaranya banyak yang memiliki status generasi milenial. Santrisantri ini bergerak untuk upaya pemenangan dengan melakukan pendekatan melalui perbincangan-perbincangan kecil sehari-hari. Sehingga tidak nampak bahwa mereka sedang melakukan kampanye. Sementara itu, mantan santri juga digunakan untuk melakukan upaya pemenangan dengan memainkan posisi yang sedang mereka peroleh setelah menjadi mantan santri. Yang perlu dicatat di sini adalah, bahwa yang disebut santri itu bukan hanya orang yang sedang belajar di pondok pesantren, namun juga orang-orang yang menjadi pengusaha dan posisi lain yang belajar atau mematuhi Kiai-Kiai NU. Dengan demikian, Kiai bisa menggunakan 
pengaruhnya agar santri yang berstatus sebagai pengusaha itu bisa menggunakan jaringannya untuk upaya pemenangan.

Selain peran Kiai-Kiai yang sedemikian rupa, dalam dinamikanya Khofifah Indar Parawansa yang menjadi Gubernur Jawa Timur terpilih juga memiliki peran yang strategis. Dari sekian banyak jenis Nahdliyin, salah satu diantaranya adalah muslimat. Kelompok ini yang kemudian banyak digerakkan oleh Khofifah. Dia selalu ada di barisan depan setiap ada penggerakan muslimat. Pada dasarnya memang pihak JKSN lebih suka menggerakkan kelompok perempuan daripada laki-laki. Karena kelompok perempuan dinilai lebih mudah dikumpulkan daripada laki-laki karena terhalang waktu bekerja. Selain itu, kelompok perempuan ini dinilai lebih kompak dan bisa diajak bekerjasama. Dengan demikian, kelompok ini bisa diajak untuk bersamasama melakukan upaya pemenangan di lapangan tanpa mengharapkan imbalan. Sementara di Pamekasan, penyebab kegagalan JKSN dan para Kiai adalah karena Kiai-Kiai besar yang banyak yang ke 02. Karena meskipun mereka bergabung dengan NU, mereka juga bergabung dengan FPI yang sudah jelas memilih 02, dan itu juga sudah sedemikian rupa sejak pilpres 2014.

Sementara di daerah Pacitan dan Bondowoso, JKSN dan Kiai gagal untuk memengaruhi masyarakat agar memilih 01 karena masyarakat di sana banyak tidak melirik 01 namun melirik SBY (Demokrat), dan pada saat itu Demokrat adalah bagian dari koalisi Prabowo Subianto, sehingga otomatis mereka memilih 02 . Kiai/Ulama/Tokoh agama adalah satu dari sebagian yang masuk pada formula dan penerapan strategi yang dilakukan oleh TKD, selain ibu-ibu muslimat, masyarakat santri, golongan millennial dan pengusaha. Sebab perempuan sering kali menjadi sasaran empuk media sehingga perlu diliterasi dalam pemahaman konteks media massa (Setiyaningsih, \& Jatmikowati, 2019; Setiyaningsih, 2020; Setiyaningsih et al., 2020).

Divisi jajaran korwil (koordinator wilayah) diisi oleh para politisi dan/Kepala Daerah di hampir seluruh provinsi di Jawa Timur dari 38 Kabupaten/Kota, dimana kepala daerah ini juga bergabung pada partai yang mendukung koalisi Jokowi dan Kiai Ma'ruf pada pemilihan presiden 2019, dimana koalisi itu diisi oleh sembilan parpol, yaitu enam partai parlemen (PDI-P, PKB, HANURA, NASDEM, GOLKAR dan PPP) dan tiga non-parlemen (PSI, PERINDO DAN PKPI). Keberadaan para kepala daerah ini dirasa mampu mendongkrak suara Jokowi dan Kiai Ma'ruf Amin di Jawa Timur ini adalah hal yang mudah dilakukan untuk meraih kemengangan di Jawa Timur, tapi hanya menjadi sebuah jalan pintas untuk meraih kemenangan, karena jabatan yang mereka miliki harus membuat mereka berdiri diatas banyak pihak, dan figur kandidat tetap menjadi pertimbangan utama bagi konstituen untuk menentukan arah pilihan mereka.

Berpedoman pada Undang-Undang Nomor 7 Tahun 2017 pasal 281 sebagai dasar hukum mengenai kepala daerah atau wakil kepala daerah bisa menjadi juru kampanye atau anggota tim sukses bagi calon presiden dan calon wakil presiden tertentu. Dalam undang-undang juga telah diatur mengenai kepala daerah yang boleh melakukan kampanye dengan persyaratan mengajukan perizinan terlebih dahulu, dan boleh melakukan kampanye di hari libur. Hal ini juga memiliki pertimbangan, dimana kepala daerah ini dalam berkampanye tidak bisa menggunakan fasilitas negara, dengan pengecualian dimana bisa menggunakan fasilitas pengamanan bagi pejabat negara. Kepala Daerah juga diwajibkan mengambil cuti dalam masa kampanye sebagaimana yang tercantum dalam pasal 60, 64, serta 281 UU tentang pemilu. Apabila dilihat pada peraturan KPU No. 23 tahun 2018, pasal 62 menyebutkan bahwa jajaran Menteri dan Kepala daerah yang terlibat sebagai anggota Tim Kampanye dan/atau Pelaksana Kampanye dapat diberikan cuti di luar tanggungan negara.

\section{Strategi Kampanye Pelibatan Tokoh agama oleh Jokowi Ma'ruf}

Dalam Pemenangan Joko Widodo dan Kiai Ma'ruf Di Jawa Timur dua elemen penting yang utama dan terbesar adalah TKD Jawa Timur dan JKSN dan diiringi dengan tim relawan lainnya. 
Dapat dikatan di Jawa Timur semua berada dalam satu komando TKD Jawa Timur Jokowi- Kiai Ma'ruf. Seperti yang sudah peneliti uraikan diatas bahwa dengan adanya KH. Ma'ruf Amin sebagai wakil presiden Jokowi, Maka membuat NU di Jawa Timur memiliki porsi dan peranan yang besar dalam berkampanye. TKD menggandeng para Tokoh NU, sehingga para Kiai-kiai di Jawa Timur masuk dalam tim.

Sebelumnya peneliti telah menguraikan mengenai TKD yang tidak menyertakan tokoh agama dan Kiai yang memiliki ideologi dan Islam radikal. Namun disampaikan kembali oleh Otman Ralibi, bahwa TKD Jawa Timur melakuka pendekatan dan komunikasi dengan kelompok dan tokoh agama seperti itu dengan tujuan untuk mengkomunikasikan bahwa apapun hasilnya mereka tidak melakukan pertentangan, dan menghormati hasil keputusan yang ada.

Sikap Toleransi dari TKD untuk mempersilahkan masyarakat lain, bahkan tokoh agama sekalipun untuk menjatuhkan pilihan kepada Prabowo-Sandi terbuka lebar, hanya saja mereka diharap tidak menentang hasil dari KPU. Seperti yang diketahui penentangaan dan aksi protes mengenai kemenangan Jokowi dan Kiai Ma'ruf terjadi dengan tuduhan kecurangan. Ketokohan Kiai sebagai mediator politik tidak hanya sekedar mendongkrak suara Jokowi di Jawa Timur, menurut Otman Ralibi selaku Responden, menyatakan bahwa andil dari tokoh agama juga meningkatkan partisipasi masyarakat dalam pemilihan dari tahun sebelumnya. Menurut KPU Provinsi Jawa Timur Pemilih di Jawa Timur pada pemilihan umum 2019 naik sebesar 5 Juta Jiwa dari Pemilihan Gubernur 2018.

Bentuk Kerjasama TKD dengan para Kiai tidak berhenti sampai disitu saja. Tapi hingga Lintas agama. Para pemimpin umat seperti para Pendeta juga turut beperan memenangkan Jokowi dan Kiai Ma'ruf. Para Tokoh agama tersebut sudah secara terbuka memberikan dukungan kepada Jokowi dan Kiai Ma'ruf. Dan mereka juga secara terbuka menghimbau para jamaahnya untuk memilih Jokowi di tanggal 17 April. Hal ini berlaku bagi tokoh agama manapun, baik itu Islam, Kristen, Katholik, Hindu, Buddha, dan lainnya. TKD merasakan peran tokoh agama sangat luar biasa di momen pilpes kali ini.

TKD Jawa Timur tidak memiliki kriteria khusus mengenai Kiai yang mereka gandeng, sama seperti JKSN. Dan pada intinya mereka memannfaatkan Kiai-kiai lokal yang ada di kabupaten/kota yang ada di Jawa Timur. Karena dengan menggunkan kiai lokal akan dirasa lebih efektif, karena instruksi, himbauan yang diberikan dapat di terima langsung oleh masyarakat. Dan para Kiai ini lebih paham bagaimana karakteristik masyarakat yang ada disekitarnya. Walupun di Madura adalah Lumbung bagi Prabowo dan Sadi, tapi terdapat Kiai NU yang Dukung Jokowi.

Tidak hanya dengan para tokoh Agama, TKD juga bersama para politikus. Dalam struktur Tim Kampanye Jokowi terdapat 38 kepala daerah di Jawa Timur yang menjadi tim pemenangan Jokowi, masuk pada jajaran koordinator di tiap-tiap wilayah. Dengan menggandeng Kiai di Jawa Timur tanpa ada kriteri-kriteria tertentu. TKD juga bekerjasama dengan JKSN, dengan bentuk koordinasi untuk memaksimalkan kampanye Jokowi di daerah- daerah di Jawa Timur. Kerjasama itu juga berupa penempatan saksi di kecamatan saat penghitungan suara oleh relawan JKSN.

JKSN dengan memaksimalkan jaringannya, dan tidak hanya memamksimalkan suara Jokowi-Kiai Ma'ruf Amin di Jawa Timur, tetapi Juga Hingga di luar Jawa Timur, dan berjalan bersama Kepala Daerah setempat yang sudah mengetahui bagaimaa karaktristik masyarakatnya. Dalam setiap strategi tentu menemui hambatan, namun hambatan ini langsung diterima oleh Kiai Ma'ruf Amin yang jalannya dicegah di Pamekasan. Pamekasan darah paling ujung utara daerah Madura yang juga lumbung Prabowo-Sandi, sehingga Kiai ma'ruf kurang diterima di saat itu.

TKD sendiri tidak memiliki strategi kampanye khusus bagi para Kiai. Karena para Kiai memiliki cara sendiri untuk melakukan pendekatan masyarakat. Dapat berupa dakwah, dan para tim relawan lainnya dipersilahkan memiliki caranya sendiri- sendiri.JKSN memiliki kekuatan sendiri dalam mengkampanyekan Jokowi dan Kiai Ma'ruf. JKSN yang sudah memiliki akses dan struktur pasca pilgub Jawa Timur dapat, dan menampatkan Khofifah Indar Parawansa sebagai penasihat 
JKSN dan juga daya tarik bagi ibu-ibu muslimat. JKSN juga memiliki model yang bernama silent majority.

Mengenali lebih dalam karakteristik masyarakat terutama warga nahdliyin, kaum santri dan masyarakat indonesia yang dapat dibidik sebagai pemilih dan diikut sertakan sebagai bagian dari tim kampanye. Silent majority mampu menjadi massa nyata bagi kemenangan Jokowi. Dengan model silent majority ini, koalisi antara kiai dan warga yang masuk dalam kategori nahdliyin ini dirasa efektif. Pemberan informasi dari mulut ke mulut secara langsung, klarifikasi hoax yang dituduhkan kepada Jokowi. Hal tersebut juga dipertegas oleh ketum JKSN Jawa Timur.

Terdapat motivasi lain, selain untuk memenangkan Jokowi dan Kiai Ma'ruf, bagi JKSN ahlussunnah waljamaah harus tetap hidup beriringan dengan masyarakat, agar masyarakat Jawa Timur khususnya tidak tergerus oleh keyakinan agama islam yang bersifat aliran keras (Radikal). Dimana Otman Ralibi, sekertaris TKD Jawa Timur juga menerangkan bahwa memenangkan Jokowi juga menyelamatkan Indonesia dari keinginan kelompok-kelompok yang ingin membangun negara khilafah.

Minimnya suara Jokowi di Madura memang sudah terjadi sejak 2014, hingga pilpres 2019. Ketokohan di Madura yang kuat membuat masyarakat Madura mengikuti yng dikatakan oleh opinion leader mereka. Hal lain muncul penyebab masyarakat Madura tidak memilih Jokowi dikarenakan, batalnya Joko Widodo menggandeng Mahfud MD, tokoh nasional dari Madura, menjadi calon wakil presiden di pilpres 2019.

Seperti yang ditulis oleh Bustami (2004) yang dikutip peneliti dari Jurnal Penelitian Sosial Keagamaan yang Berjudul-Menguji Kharisma Kiai Dalam Kehidupan Masyarakat Madura Jember Jawa Timurll dikatakan bahwa Dasar dari kepatuhan masyarakat Madura kepada sosok Kiai lebih merujuk kepada tatanan moralitas dan persoalan ukhrowi. Ukhrowi sendiri merupakan sesuatu yang berhubungan atau bersifat dengan keakhiratan. Jadi menggerus suara Jokowi dengan menggunakan isu agama di dalam masyarakat Madura akan begitu mudah dilakukan oleh pihak yang berkepentingan.

Tanpa banyak masyarakat sadari pemberitaan yang mengandung unsur hoax lalu mereka mempercayai hal itu sebagai suatu kebenaran akan mempengaruhi elektabilitas dan penurunan suara yang disebabkan krisis kepercayaan masyarakat kepada Joko Widodo

Secara keseluruhan dirasa suara Jokowi dan Kiai Ma'ruf di tanah Madura kalah dari Prabowo-Sandi, hanya di Kabupaten Bangkalan Jokowi Dan Kiai Ma'ruf Unggul. seperti yang di realize KPU Provinsi Jawa Timur, Paslon 01 memperoleh suara 440.129 dan paslon 02 sebesar, 322.131. Di kabupaten Sampang Paslon 01 memperoleh 187. 189 sedangkan paslon 02 dengan suara 570.597, dan di Kabupaten Pamekasan Jokowi dan Kiai Ma'ruf memperoleh 102.931 dan Parabowo sandi sebesar 531.561. Dan di kabupaten Sumenep paslon 01 memperoleh 242.305 dan paslon 02 memperoleh 436.931.

Pada JKSN sendiri, bagi mereka dengan mengerahkan Kiai Lokalnya dan mengesampingkan sistem egaliter atau menganggap semua kiai sama dan memiliki peran dan porsi yang sama pada pemilihan ini tanpa membedakan Kiai tersebut berasal dari daerah mana dan keturunan siapa, melainkan focus kepada dukungan kiai tersebut dan menetralisir hoax yang menyerang Joko Widodo.

Melihat hasil penelitian dan pembahasan maka dapat dilihat peran spesifik Kiai bersama Tim Kampanye Daerah Jawa Timur untuk memenangkan Joko Widodo dan Kiai Ma'ruf, yaitu sebagai, Opinion Leader, Mediator Politik, dan Vote Getter. Dapat diketahui dalam hal ini wujud kegiatan dan realisasinya berupa ceramah atau dakwa, dengan keterampilan komunikasi yang dimiliki dengan menyampaikan pesan-pesan mengenai himbauan-himbauan untuk menggunakan hak suara dan memilih sosok pemimpin yang tepat. Kemampuan komunikasi yang dimiliki Kiai juga tidak bisa disepelekan, dengan kemampuan berorasi yang sudah dimiliki melalui proses secara otodidak yang didapat dari jam terbang dakwah yang tinggi. Kiai memang kelompok minoritas, tetapi kiai juga 
memiliki basis massa, dengan karisma dan kapasitas yang dimiliki kiai mampu menggaet massa, oleh karena itu para tokoh agama ini sering kali menjadi target para elit politik dan tim sukses untuk membangun dan memperkuat massa basis dukungan politik.

Sebagai tokoh mediator politik Kiai juga memiliki peran dan kedudukan, tidak hanya di masyarakat tetapi kiai juga memiliki peran di pesantrennya. Kiai dan pesantren merupakan satu dari sekian perangkat yang bisa digunakan untuk menjalankan aktivitas dakwah seperti yang dilakukan Kiai Asep sebagai Dewan Pembina JKSN mendeklarasikan sebagai bagian tim pemenangan Jokowi dan Kiai Ma'ruf di Pondok Pesantren Amanatul Uma Pacet, Mojokerto. Kharisma dan kapasitas yang dimiliki kiai beserta jaringannya di masyarakat menjadi modal politik yang bisa digunakan secara optimal dalam memenangkan kandidat terutama dalam mendulang suara karena mereka memiliki basis massa yang nyata. Kiai yang berafiliasi dengan TKD Jawa timur untuk memenangkan Joko Widodo dan Kiai Ma'ruf juga terlibat dalam memobilisasi dukungan politik electoral. Kiai juga sebgai sosok dinilai memiliki modal kharismatik dilautan masyarakat jawa timur. Kerap kali kiai juga dianggap memiliki kemampuan yang lebih terhadap penggerakan masyarakat khususnya dalam menggerakan pilihan politik. Seperti yang disampaikan Sekjen JKSN KH. Zahrul Azhar As'ad bahwa himbauan para kiai kampung dan kiai langgar dapat diterima dan direalisasikan oleh masyarakat yang bersangkutan.

Selain JKSN yang ada di jawa timur Tim Kampanye Daerah 01 Jawa Timur Juga memaksimalkan jaringan gerakan Relawan yang mendukung Jokowi \& $\mathrm{KH}$. Ma'ruf Amin diantaranya adalah Jaringan Alumni, seperti Alumni Perguruan Tinggi di Jawa Timur Alumni SMA Surabaya \& Jawa Timur, masih banyak lagi Relawan pendukung Jokowi Amin, seperti BARA JP, JOMA Jatim, BangJO Jatim, dan sebagainya.Tim Kampanye Daerah Jawa Timur memfasilitasi dan mendukung penuh segala aktifitas yang di buat untuk mengkampanyekan dan memenangkan Capres No 01 Jokowi Amin.

\section{4 | SIMPULAN DAN SARAN}

Strategi komunikasi politik Tim Kampanye Daerah Jawa Timur Joko Widodo - KH. Ma'ruf Amin dan Relawan Jokowi menggunakan strayer saat pemilihan Presiden, oleh sebab itu strategi TKD Jatim menjadi penentu (opinion leader) untuk menentukan vote Getter dan menjadi mediator politik ke berbagai pihak yang mempunyai peranan penting untuk meningkatkan suara di Jawa timur. Opinion leader yang efektif adalah melibatkan tokoh agama utamanya kiai NU yang menjadi penjaga gerbong massa di Propinsi Jawa Timur. Hambatan dapat diatasi melalui koordinasi yang massif dapat mengerucutkan suara dan menggiring opini menjadi kampanye yang efektif. Dimana kampanye diproyeksikan pada pembentukan citra positif calon melalui berbagai kegiatan di seluruh sektor kehidupan. Strayer, pelibatan media massa dan sosial menjadi penentu komunikasi politik di tingkat basis.

\section{REFERENSI}

Antar, V. (2004). Manajemen kampanye: panduan teoritis dan praktis dalam mengekfektifkan kampanye komunikasi. Simbiosa Rekatama Media.

Aurellia, A. I. (2021). Strategi Komunikasi Digital Pada Kampanye Politik Pilkada Era Pandemi Covid 19 (Studi Komunikasi Politik Penggunaan Media Sosial pada Pilkada Bontang 2020 Pasangan Nomer urut dua Neni Moerniaeni dan Joni Muslim). Universitas Pertamina.

Cangara, H. (2014). Komunikasi Politik: Konsep, Teori dan Strategi. (Rajawali P).

Dicky, P. Y. (2020). PENGARUH BUDAYA POLITIK MASYARAKAT MINANGKABAU TERHADAP PARTISIPASI POLITIK MASYARAKAT PADA PEMILIHAN PRESIDEN DAN WAKIL 
PRESIDEN TAHUN 2019 DI KOTA PADANG. Universitas Andalas.

Fatchuriza, M., \& Prasojo, T. A. (2019). Pelaksanaan Pemilihan Gubernur Jawa Tengah Tahun 2018 Dalam Meningkatkan Partisipasi Politik Dengan Media Yang Tepat. AS-SIYASAH: Jurnal IImu Sosial Dan IImu Politik, 4(2), 73-81.

Fatimah, S. (2018). Kampanye sebagai Komunikasi Politik. Resolusi: Jurnal Sosial Politik, 1(1), 516.

Hasfi, N. (2019). Komunikasi Politik Di Era Digital. Politika: Jurnal Ilmu Politik, 10(1), 93-111.

Hasyim, N. M. (2016). Konstruksi Citra Maskulinitas Calon Presiden (Study Analisis Framing Model Gamson Dan Modigliani Pada Pemberitaan Koran Harian Kompas Dan Jawa Pos Edisi Juni 2014). Profetik: Jurnal Komunikasi, 9(1).

J.Moleong, L. (2014). Metode Penelitian Kualitatif , Edisi Revisi. PT Remaja Rosdakarya.

KPU. (2019). Partisipasi Pemilih Pemilu 2019 Provinsi Jawa Timur. https://jatim.kpu.go.id/dc1tingkat-provinsi/

Leiliyanti, E., Diyantari, D., \& Irawaty, I. (2017). Transcoding Wacana Konstruksi dan Kontestasi Citra Jokowi dan Prabowo dalam Media Sosial pada Masa Kampanye Pilpres 2014. Mozaik Humaniora, 17(2), 192-213.

Miles,M.B, Huberman,A.M, dan Saldana, J. (2014). Qualitative Data Analysis, A Methods Sourcebook, Edition 3. Terjemahan Tjetjep Rohindi Rohidi, UI-Press. Sage Publications.

Neuman, W. R., Neuman, R. W., Just, M. R., \& Crigler, A. N. (1992). Common knowledge: News and the construction of political meaning. University of Chicago Press.

Noor, F. (2018). Pilkada, Peran Partai dan Konstelasi Pragmatis: Kajian Atas Pilgub Banten, DKI Jakarta, Jateng dan Jatim Tahun 2017-2018. Jurnal Penelitian Politik, 15(2), 179-196.

Pura, A. K. (2019). Strategi Pemenangan Dalam Pemilihan Umum Calon Legislatif Partai Gerindra Di Desa Buo Kecamatan Loloda Kabupaten Halmahera Barat Tahun 2019. Jurnal Politico, $8(2), 1-10$.

Pusparimba, T. M., Djuyandi, Y., \& Solihah, R. (2021). Strategi Pemenangan Jokowi dan Ma'ruf Amin dalam Pemilihan Presiden 2019 melalui Pencitraan Politik. PERSPEKTIF, 10(2), 555561.

S.P., N., \& \& Phillips L.M. (2003). How literacy in its fundamental sense is central to scientific literacy, Science Education. modern.

Sanjaya, L. D., Naryoso, A., Yulianto, M., Gono, J. M., \& Ayun, P. Q. (2016). Political Public Relations Campaign for Election of Mayor and Deputy Mayor of Solok Period 2016-2020, Creative Design Coordinator Division. Interaksi Online, 4(2), 1-10.

Setiyaningsih, L. A., \& Jatmikowati, S. H. (2019). Media Baru Dalam Komodifikasi Waktu Luang Ibu Rumah Tangga. ETTISAL: Journal of Communication, 4(1), 23-32.

Setiyaningsih, L. A. (2020). MEDIA PANICS IBU RUMAH TANGGA SETELAH MENGAKSES BERITA COVID-19 (2020). Jurnal Nomosleca, 6(2), 101-110.

http://jurnal.unmer.ac.id/index.php/n/article/view/4721/2594

Setiyaningsih, L. A., Fahmi, M. H., \& Sawidodo, F. (2020). Media Referensi Berbasis Teknologi Facebook Bagi Wartawan Dalam Menyusun Berita. Jurnal Spektrum Komunikasi, 8(2), 159_ 176. https://doi.org/10.37826/spektrum.v8i2.101

Sugiarto, B., Pratiwi, O.C, \& A. (2014). Strategi Pemenangan Dalam Pemilihan Kepala Daerah. Jurnal Masyarakat, Kebudayaan Dan Politik., 27(3), 143-151.

Sultoni, K. B., \& Harsasto, P. (2020). MEDIA DAN POLITIK: STRATEGI KAMPANYE PARTAI PERINDO DAN PSI DALAM MEMPENGARUHI SUARA PEMILIH DI KOTA SEMARANG. Journal of Politic and Government Studies, 9(2), 171-180. 
Suryadi, K., Sukmayadi, V., \& Saria, N. (2021). POLITICAL COMMUNICATION STRATEGIES OF NEW POLITICAL PARTY. Makna: Jurnal Kajian Komunikasi, Bahasa, Dan Budaya, 8(1), 94105.

Suwardi, Harsono, Sendjaja, S. D. dan B. S. (2012). Politik Demokrasi dan Manajemen Komunikasi. YogyakartaPress.

Triono, M. A., \& Setiyaningsih, L. A. (2017). Desain Disonansi Kognitif Sebagai Faktor Anteseden Untuk Penguatan Kualitas Informasi Pada Website. Seminar Nasional Sistem Informasi, 1(1), 71-79. http://eprints.unmer.ac.id

Triwicaksono, Y. D. B. B., \& Nugroho, A. (2021). Strategi Komunikasi Politik Pemenangan Kepala Daerah. JURNAL LENSA MUTIARA KOMUNIKASI, 5(1), 133-145.

Waluyo, D. (2019). PEMAHAMAN DAN PRAKTIK KOMUNIKASI POLITIK PADA ERA DIGITAL. Diakom: Jurnal Media Dan Komunikasi, 2(2), 160-167. 